University of Nebraska - Lincoln

DigitalCommons@University of Nebraska - Lincoln

$5-1-2000$

\title{
Structure and magnetic properties of $\mathrm{N}$-containing $\mathrm{Nd}-\mathrm{Fe}-\mathrm{B}$ alloys prepared by mechanical alloying
}

W. Liu

International Center for Materials Physics, Institute of Metal Research, Academia Sinica, Shenyang 110015, People's Republic of China

Z.D. Zhang

International Center for Materials Physics, Institute of Metal Research, Academia Sinica, Shenyang 110015, People's Republic of China

J. Ping Liu

University of Nebraska-Lincoln, pliu@uta.edu

X.K. Sun

International Center for Materials Physics, Institute of Metal Research, Academia Sinica, Shenyang 110015, People's Republic of China

David J. Sellmyer

University of Nebraska-Lincoln, dsellmyer@unl.edu

Follow this and additional works at: https://digitalcommons.unl.edu/physicssellmyer

Part of the Physics Commons

Liu, W.; Zhang, Z.D.; Liu, J. Ping; Sun, X.K.; and Sellmyer, David J., "Structure and magnetic properties of Ncontaining Nd-Fe-B alloys prepared by mechanical alloying" (2000). David Sellmyer Publications. 56.

https://digitalcommons.unl.edu/physicssellmyer/56

This Article is brought to you for free and open access by the Research Papers in Physics and Astronomy at DigitalCommons@University of Nebraska - Lincoln. It has been accepted for inclusion in David Sellmyer Publications by an authorized administrator of DigitalCommons@University of Nebraska - Lincoln. 


\title{
Structure and magnetic properties of $\mathrm{N}$-containing $\mathrm{Nd}-\mathrm{Fe}-\mathrm{B}$ alloys prepared by mechanical alloying
}

\author{
W. Liu ${ }^{\text {a) }}$ and Z. D. Zhang \\ International Center for Materials Physics, Institute of Metal Research, Academia Sinica, \\ Shenyang 110015, People's Republic of China \\ J. P. Liu \\ Center for Materials Research and Analysis, University of Nebraska, Lincoln, Lincoln, \\ Nebraska 68588-0113 \\ X. K. Sun \\ International Center for Materials Physics, Institute of Metal Research, Academia Sinica, \\ Shenyang 110015, People's Republic of China \\ D. J. Sellmyer \\ Center for Materials Research and Analysis, University of Nebraska, Lincoln, Lincoln, \\ Nebraska 68588-0113
}

The structure and magnetic properties of $\mathrm{Nd}_{2} \mathrm{Fe}_{14} \mathrm{BN}_{\delta}$-based alloys prepared by mechanical alloying have been investigated. For the $\mathrm{Nd}_{14} \mathrm{Fe}_{78} \mathrm{~B}_{8} \mathrm{~N}_{y}$ series, a large amount of $\mathrm{NdN}, \alpha$-Fe, and a small $\mathrm{Nd}_{2} \mathrm{Fe}_{14} \mathrm{~B}$ phase are observed in $\mathrm{x}$-ray diffraction patterns. With increasing $\mathrm{Nd}$ content, the amount of the $\mathrm{Nd}_{2} \mathrm{Fe}_{14} \mathrm{BN}_{\delta}$ phase increases and $\alpha$-Fe decreases gradually. When $x \geqslant 25$ in the

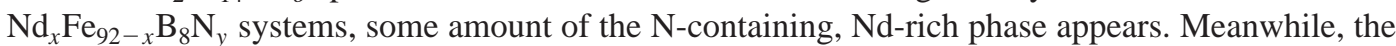
content of the nitrogen in the $\mathrm{Nd}_{2} \mathrm{Fe}_{14} \mathrm{BN}_{\delta}$ phase decreases and, correspondingly, the Curie temperature decreases. The coercivity and the maximum magnetic energy product of this series attain maxima at $x=25$. A coercivity as high as $20 \mathrm{kOe}$ has been achieved. The effect of nitrogen on the formation, composition, and magnetic properties of the $\mathrm{Nd}_{2} \mathrm{Fe}_{14} \mathrm{BN}_{\delta}$ compound is discussed. (C) 2000 American Institute of Physics. [S0021-8979(00)22208-1]

\section{INTRODUCTION}

Since Coey and Sun succeeded in producing a new family of rare-earth-transition-metal $(\mathrm{R}-\mathrm{T})$ intermetallic nitrides $\mathrm{R}_{2} \mathrm{Fe}_{17} \mathrm{~N}_{3-\delta}$, by means of a gas-solid reaction, ${ }^{1}$ other series such as $\mathrm{RFe}_{11} \mathrm{TiN}_{\delta}$ and $\mathrm{R}_{2} \mathrm{Fe}_{14} \mathrm{BN}_{x}$ compounds have been reported. ${ }^{2-5}$ In our recent work, ${ }^{6}$ the quaternary interstitial nitrides $\mathrm{R}_{2} \mathrm{Fe}_{14} \mathrm{BN}_{0.1}(\mathrm{R}=\mathrm{Nd}$ and $\mathrm{Sm})$ were synthesized by arc melting. It is particularly interesting that $\mathrm{B}$ can be replaced by pyrolytic boron nitride $(p-\mathrm{BN})$ without an extra nitrogenization treatment during the synthesizing process. The $\mathrm{B}-\mathrm{N}$ bonding can be broken by arc melting, and the combination of the atomic $\mathrm{B}$ and $\mathrm{N}$ with rare-earth and transition metal atoms leads to the formation of the interstitial $\mathrm{R}_{2} \mathrm{Fe}_{14} \mathrm{BN}_{0.1}$ compound. ${ }^{6}$

Mechanical alloying (MA) as a preparation method of samples has attracted much attention in synthesis of materials, particularly, rare-earth permanent magnets. Since magnetic materials were first prepared by mechanical alloying by Schultz and co-workers, ${ }^{7}$ rather high values of coercivity have been achieved by MA and subsequent heat treatment in some R-T alloy systems such as $\mathrm{SmFe}_{7} \mathrm{~N}_{\delta},{ }^{8} \mathrm{Sm}-\mathrm{Fe}-\mathrm{Ti},{ }^{9}$ and $\mathrm{Dy}-\mathrm{Fe}-\mathrm{C}{ }^{10}$ Although $p$-BN can be decomposed completely into nitrogen and boron only at about $2500{ }^{\circ} \mathrm{C},{ }^{11}$ the $p$-BN compound can be partially decomposed by milling until an amorphous phase containing $\mathrm{B}$ and $\mathrm{N}$ is formed ac-

a) Author to whom correspondence should be addressed; electronic mail: wliu@imr.ac.cn cording to our previous work. ${ }^{12}$ Mechanical alloying and subsequent annealing cause the milled $p$-BN to combine with pure $\mathrm{Nd}$ and $\mathrm{Fe}$ powders to form the $\mathrm{Nd}_{2} \mathrm{Fe}_{14} \mathrm{BN}_{\delta}$ alloys. ${ }^{12}$

In this article, the effect of different $\mathrm{Nd}$ content on the structure and magnetic properties of $\mathrm{Nd}_{2} \mathrm{Fe}_{14} \mathrm{BN}_{\delta}$-based alloys prepared by mechanical alloying is reported.

\section{EXPERIMENTAL DETAILS}

Elemental powders of $\mathrm{Nd}, \mathrm{Fe}$, and $p$-BN with purity higher than $99.5 \%$ were mixed according to the composition of $\mathrm{Nd}_{x} \mathrm{Fe}_{92-x} \mathrm{~B}_{8} \mathrm{~N}_{y}$ ( $y$ represents the $\mathrm{N}$ content in raw materials) in which one $\mathrm{B}$ atom was replaced by one $p$-BN molecule milled for $5 \mathrm{~h}$ and $\mathrm{N}$ was not taken into account. Mechanical alloying of the mixtures was carried out using a self-made high-energy ball mill for $5 \mathrm{~h}$. The condition for MA was the same as described in Ref. 12. The MA powders were annealed at $750{ }^{\circ} \mathrm{C}$ for $30 \mathrm{~min}$ in a vacuum furnace directly connected to a closed glovebox. X-ray diffraction (XRD) analysis of the powder samples was conducted using $\mathrm{Cu} K \alpha{ }^{12}$ The content of nitrogen in the MA samples was determined by a TC-436 oxygen-nitrogen determinator. ac susceptibility was measured in the temperature range of $300-773 \mathrm{~K}$ with an ac field of $16 \mathrm{~A} / \mathrm{m}$ and frequency of 1.13 $\mathrm{kHz}$. The powders were embedded in epoxy resin to form magnetically isotropic magnets. The magnetic properties were measured at room temperature using a pulsed magnetometer at fields up to $15 \mathrm{~T}$. The dilution effect was neglected and the density of the powdered samples was accounted for to be $7.6 \mathrm{~g} / \mathrm{cm}^{3}$. 


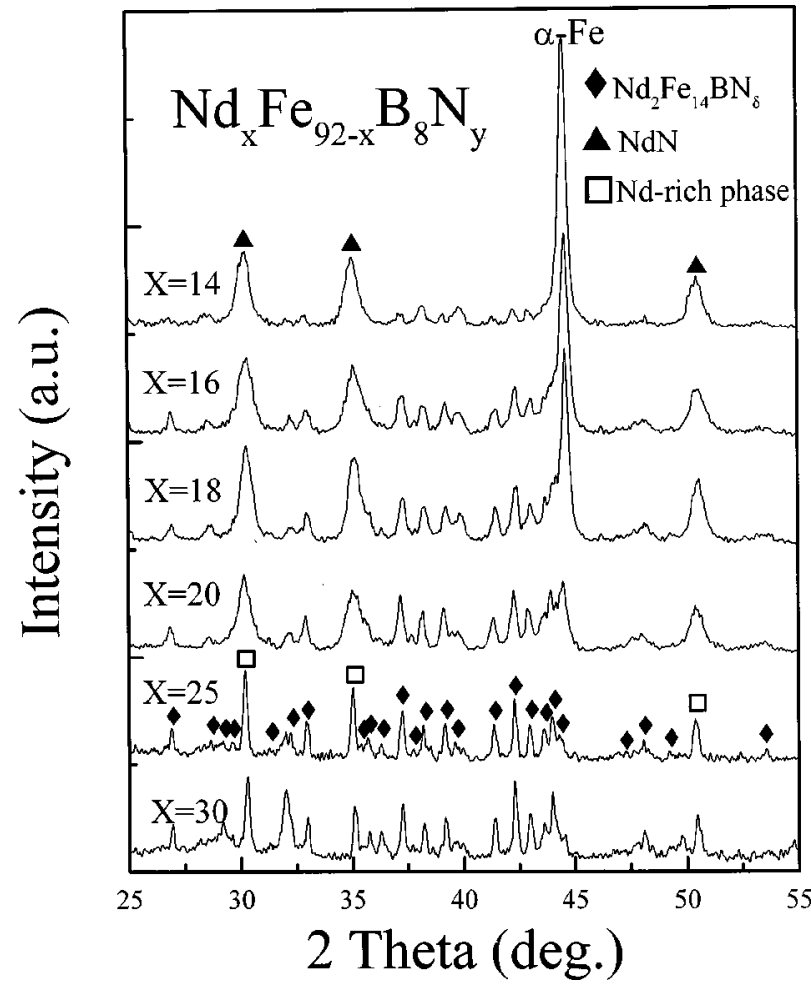

FIG. 1. X-ray diffraction patterns of $\mathrm{MA} \mathrm{Nd}_{x} \mathrm{Fe}_{92-x} \mathrm{~B}_{8} \mathrm{~N}_{y}$ alloys annealed at $750{ }^{\circ} \mathrm{C}$ for $30 \mathrm{~min}$

\section{RESULTS AND DISCUSSION}

$\mathrm{X}$-ray diffraction patterns of MA $\mathrm{Nd}_{x} \mathrm{Fe}_{92-x} \mathrm{~B}_{8} \mathrm{~N}_{y}$ alloys annealed at $750{ }^{\circ} \mathrm{C}$ for $30 \mathrm{~min}$ are shown in Fig. 1. It is seen from Fig. 1 that a large amount of $\mathrm{NdN}, \alpha$-Fe, and a small $\mathrm{Nd}_{2} \mathrm{Fe}_{14} \mathrm{BN}_{\delta}$ phase $(\delta$ represents the quantity of the possible interstitial atoms) is observed in the samples for $x=14$. It is clear that most of the $\mathrm{Nd}$ atoms in the samples have combined with nitrogen originating from the $p$-BN decomposition. With increasing $\mathrm{Nd}$ content, the amount of the $\mathrm{Nd}_{2} \mathrm{Fe}_{14} \mathrm{BN}_{\delta}$ phase increases and $\alpha$-Fe in the sample decreases gradually. When $x \geqslant 25$, the main phase is $\mathrm{Nd}_{2} \mathrm{Fe}_{14} \mathrm{~B}$ type with some amount of the N-containing, Nd-rich phase. The open square symbol in Fig. 2 stands for the Nd-rich phase, and these peaks belong to the fcc structure according to the XRD analysis of the MA samples. It was reported that a fcc structural Nd-rich intergranular phase stabilized by oxygen with composition of nearly 95 at. $\% \mathrm{Nd}$ and 5 at. \% Fe existed in the sintered or die-upset $\mathrm{R}-\mathrm{Fe}-\mathrm{B}$ alloys. ${ }^{13,14} \mathrm{It}$ is seen that the NdN phase with the broad XRD peaks for $x<25$ may coexist with a small Nd-rich phase, and when $x$ $\geqslant 25$, they are transformed into the N-containing, Nd-rich phase, although their positions of the XRD peaks are very close. The change of the shape of XRD peaks and the results below (Fig. 3) support this point of view. However, $\alpha$-Fe disappears in the samples with $x \geqslant 25$. According to our previous work, ${ }^{12}$ the $p$-BN can be decomposed into boron and nitrogen by the MA process, and most of the atomic $\mathrm{N}$ combines with $\mathrm{Nd}$ to form $\mathrm{NdN}$ and the $\mathrm{B}$ contributes to the $\mathrm{Nd}_{2} \mathrm{Fe}_{14} \mathrm{~B}$-type phase. The more free $\mathrm{Nd}$ that does not combine with nitrogen, the more the $\mathrm{Nd}_{2} \mathrm{Fe}_{14} \mathrm{~B}$-type phase is formed. This is why high-Nd content is needed to form the

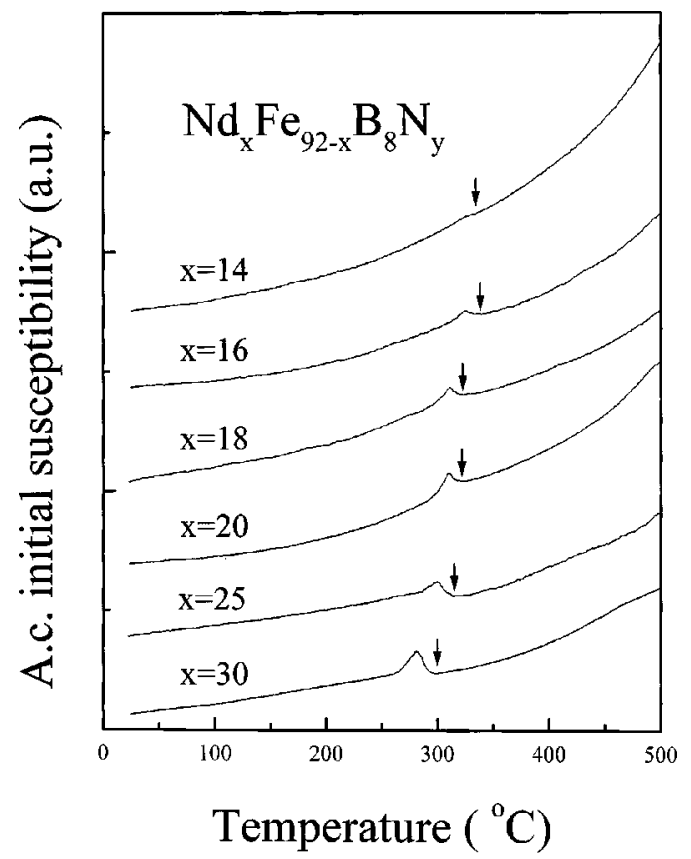

FIG. 2. Temperature dependences of ac susceptibility of MA $\mathrm{Nd}_{x} \mathrm{Fe}_{92-x} \mathrm{~B}_{8} \mathrm{~N}_{y}$ alloys annealed at $750{ }^{\circ} \mathrm{C}$ for $30 \mathrm{~min}$.

$\mathrm{Nd}_{2} \mathrm{Fe}_{14} \mathrm{~B}$ phase in this system. It is thought that the thermodynamics depends on the competition of all components in the alloys, and the existence of $\mathrm{Nd}, \mathrm{Fe}$, and $\mathrm{B}$ favors the formation of the $\mathrm{Nd}_{2} \mathrm{Fe}_{14} \mathrm{~B}$-type phase. This results in that $\mathrm{NdN}$ ceases forming for high-Nd content, although it most likely is the most stable phase in the system.

The temperature dependences of the ac susceptibility of $\mathrm{Nd}_{x} \mathrm{Fe}_{92-x} \mathrm{~B}_{8} \mathrm{~N}_{y}$ alloys annealed at $750{ }^{\circ} \mathrm{C}$ for $30 \mathrm{~min}$ are given in Fig. 2. The Curie temperatures are noted by the arrows in Fig. 2. For the sample with $x=14$, a rather small signal corresponding to the Curie temperature has been found because of a very small amount of the hard-magnetic $\mathrm{Nd}_{2} \mathrm{Fe}_{14} \mathrm{~B}$ phase. Based on these facts and the assumption that the Curie temperature is linearly dependent on nitrogen content, the composition of the hard-magnetic phase in the

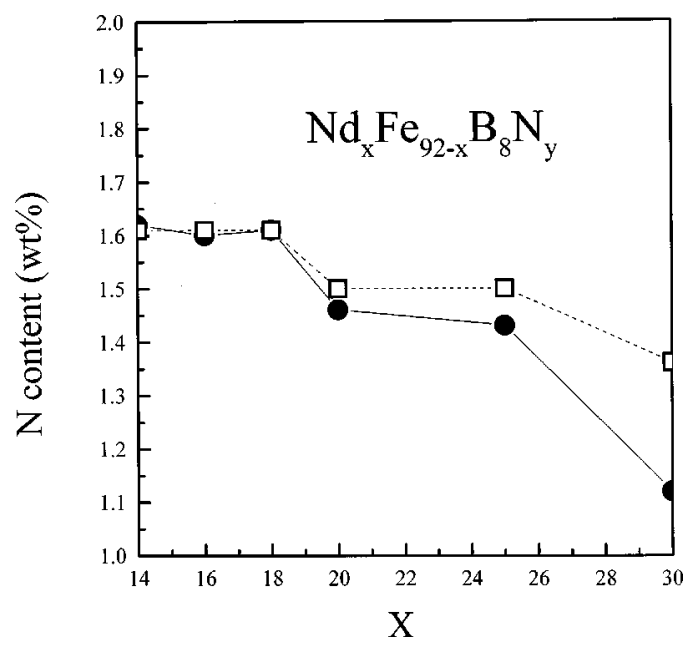

FIG. 3. Relationship between $\mathrm{N}$ and $\mathrm{Nd}$ content of $\mathrm{MA} \mathrm{Nd}_{x} \mathrm{Fe}_{92-x} \mathrm{~B}_{8} \mathrm{~N}_{y}$ alloys annealed at $7500^{\circ} \mathrm{C}$ for $30 \mathrm{~min}$. 


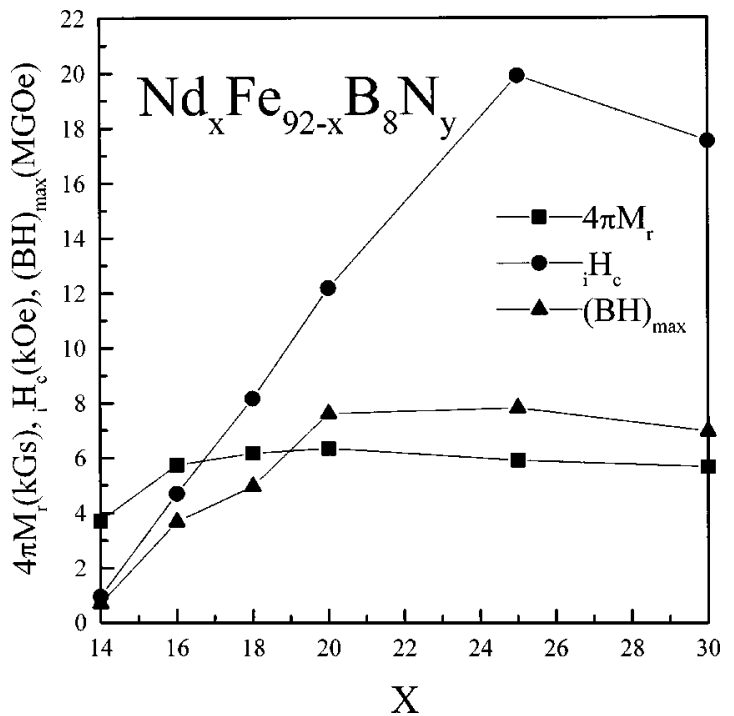

FIG. 4. Composition dependences of the magnetic properties of MA $\mathrm{Nd}_{x} \mathrm{Fe}_{92-x} \mathrm{~B}_{8} \mathrm{~N}_{y}$ alloys annealed at $750{ }^{\circ} \mathrm{C}$ for $30 \mathrm{~min}$.

sample with $x=16$ is close to $\mathrm{Nd}_{2} \mathrm{Fe}_{14} \mathrm{BN}_{0.25}{ }^{12}$ The Curie temperature of $\mathrm{MA} \mathrm{Nd}_{x} \mathrm{Fe}_{92-x} \mathrm{~B}_{8} \mathrm{~N}_{y}$ powders annealed at $750{ }^{\circ} \mathrm{C}$ for $30 \mathrm{~min}$ decreases from $338^{\circ} \mathrm{C}$ for $x=16$ to $295^{\circ} \mathrm{C}$ for $x=30$ with increasing $\mathrm{Nd}$ content. The latter is slightly lower than the normally recognized value of $312^{\circ} \mathrm{C}$ for the $\mathrm{Nd}_{2} \mathrm{Fe}_{14} \mathrm{~B}$ compound, which might be due to the fact that the structure of the phase made by MA and the annealing is not as perfect as that of the as-cast $\mathrm{Nd}_{2} \mathrm{Fe}_{14} \mathrm{~B}$ phase.

The relationship between the nitrogen and the $\mathrm{Nd}$ content in the alloys is given in Fig. 3 for MA $\mathrm{Nd}_{x} \mathrm{Fe}_{92-x} \mathrm{~B}_{8} \mathrm{~N}_{y}$ powders annealed at $750{ }^{\circ} \mathrm{C}$ for $30 \mathrm{~min}$. The open-box symbol with the dashed line represents the values of nitrogen wt $\%$ in raw materials, and the solid circle with the solid line represents the experimental results after the process of MA and subsequent annealing. It is found that the $\mathrm{N}$ content of the samples with $x<20$ are in agreement with those of the raw materials, when $x \geqslant 20$, the $\mathrm{N}$ content reduces relatively with increasing $\mathrm{Nd}$ content in comparison with those of the raw materials. It is concluded that partial nitrogen in the samples with $x \geqslant 20$ outgasses from the samples during either MA or annealing under a high vacuum

The formation of the Nd-rich phase probably around the $\mathrm{Nd}_{2} \mathrm{Fe}_{14} \mathrm{~B}$ phase may prevent $\mathrm{N}$ from entering the interstitial sites in the $\mathrm{Nd}_{2} \mathrm{Fe}_{14} \mathrm{~B}$ lattice during the solid-state reaction. Thus, it will likely lead to a decrease of the interstitial $\mathrm{N}$ content in the $\mathrm{Nd}_{2} \mathrm{Fe}_{14} \mathrm{BN}_{\delta}$. This, in turn, will cause the lowered Curie temperature. As many groups have reported, ${ }^{1-3}$ the lattice expansion caused by the interstitial atoms in rareearth iron compounds results in a remarkably high Curie temperature. However, no evident shift in XRD peaks of the $\mathrm{Nd}_{2} \mathrm{Fe}_{14} \mathrm{~B}$-based phase is observed in this work, which might be ascribed to the small content of interstitial $\mathrm{N}$ atoms (less than 0.25 per formula unit).

Figure 4 shows the composition dependences of the magnetic properties of MA $\mathrm{Nd}_{x} \mathrm{Fe}_{92-x} \mathrm{~B}_{8} \mathrm{~N}_{y}$ alloys annealed at $750{ }^{\circ} \mathrm{C}$ for $30 \mathrm{~min}$. It can be seen from Fig. 4 that rather poor magnetic properties are achieved for $x=14$, because of the existence of a small amount of hard-magnetic phase and a large amount of $\mathrm{NdN}$ and $\alpha$-Fe. The remanence reaches a maximum at $x=20$, while the maximum energy product and intrinsic coercivity reach maxima at $x=25$. The largest value of the coercivity is $20 \mathrm{kOe}$. The Nd-rich composition is beneficial to the formation of the hard $\mathrm{Nd}_{2} \mathrm{Fe}_{14} \mathrm{~B}$ and the $\mathrm{N}$-containing, Nd-rich phase, although some amount of $\mathrm{Nd}$ in the samples combines with nitrogen from decomposition of $p$-BN during mechanical alloying. Therefore, a higher coercivity is attributed to the formation of the hard $\mathrm{Nd}_{2} \mathrm{Fe}_{14} \mathrm{~B}$ as a major phase and the $\mathrm{N}$-containing, Nd-rich phase, which may play a similar role as the Nd-rich phase in sintered $\mathrm{Nd}-$ $\mathrm{Fe}-\mathrm{B}$ magnets. In addition, excess $\mathrm{Nd}$ in the samples with $x>25$ also leads to the slight decrease of the coercivity.

\section{SUMMARY}

A mechanical alloying route for synthesizing the interstitial $\mathrm{Nd}_{2} \mathrm{Fe}_{14} \mathrm{BN}_{\delta}$ compound has been applied. The nitrogen content in the interstitial compounds and the total nitrogen content in the alloys can be controlled to some extent by changing the $\mathrm{Nd}$ content. The formation of the $\mathrm{N}$-containing, Nd-rich phase decreases the $\mathrm{N}$ content in the $\mathrm{Nd}_{2} \mathrm{Fe}_{14} \mathrm{BN}_{\delta}$ compound and its Curie temperature. It may also lead to the enhancement of the intrinsic coercivity of the alloys. In the $\mathrm{Nd}_{x} \mathrm{Fe}_{92-x} \mathrm{~B}_{8} \mathrm{~N}_{y}$ systems, the optimal magnetic properties are achieved with $x=25$.

\section{ACKNOWLEDGMENTS}

This work has been supported by the National Natural Science Foundation of China under Project Nos. 59725103 and 59831010, and the U.S. NSF under Grant No. INT9812082. Two of the authors (J.P.L. and D.J.S.) were also supported by the U.S. DARPA under ARO Grant No. DAAG5J-98-1-0268.

${ }^{1}$ J. M. D. Coey and H. Sun, J. Magn. Magn. Mater. 86, L251 (1990).

${ }^{2}$ Y. C. Yang, X. D. Zhang, L. S. Kong, Q. Pan, and S. L. Ge, Appl. Phys. Lett. 58, 2042 (1991).

${ }^{3}$ X. D. Zhang, Q. Pan, S. Z. Dong, S. L. Ge, Y. C. Yang, J. L. Yang, B. S. Zhang, Y. F. Ding, and C. T. Ye, Acta Phys. Sin. 2, 537 (1993).

${ }^{4}$ X. D. Zhang, Q. Pan, S. L. Ge, Y. C. Yang, J. L. Yang, Y. F. Ding, B. S. Zhang, C. T. Ye, and L. Jin, Solid State Commun. 83, 231 (1992).

${ }^{5}$ X. C. Kou, T. S. Zhao, R. Grössinger, H. Kirchmayr, X. Li, and F. R. de Boer, Phys. Rev. B 46, 204 (1992).

${ }^{6}$ Z. D. Zhang, W. Liu, D. Zhang, X. M. Jin, X. G. Zhao, and Q. F. Xiao, J. Phys.: Condens. Matter 11, 3951 (1999).

${ }^{7}$ L. Schultz, J. Wecker, and E. J. Hellstern, J. Appl. Phys. 61, 3583 (1987).

${ }^{8}$ W. Liu, Q. Wang, X. K. Sun, X. G. Zhao, T. Zhao, Z. D. Zhang, and Y. C. Chuang, J. Magn. Magn. Mater. 131, 197 (1994).

${ }^{9}$ J. L. Yang, Q. Wang, X. K. Sun, G. Y. Zeng, M. Chen, W. Liu, X. G. Zhao, T. Zhao, and Z. D. Zhang, J. Magn. Magn. Mater. 132, 197 (1994).

${ }^{10}$ Y. C. Sui, Z. D. Zhang, Q. F. Xiao, W. Liu, X. G. Zhao, T. Zhao, and Y. C. Chuang, J. Phys.: Condens. Matter 9, 9985 (1997).

${ }^{11}$ A. W. Moore, J. Comput. Phys. 106, 6 (1990).

${ }^{12}$ W. Liu, Z. D. Zhang, X. K. Sun, J. F. He, and X. G. Zhao, J. Phys. D: Appl. Phys. 32, 1591 (1999).

${ }^{13}$ R. Ramesh, J. K. Chen, and G. Thomas, J. Appl. Phys. 61, 2993 (1987).

${ }^{14}$ J. Fidler, K. G. Knoch, H. Kronmüler, and G. Schneider, J. Mater. Res. 4, 806 (1989). 